DOI: https://doi.org/10.24867/04CG13Novakovic

\title{
PROJEKAT VIŠESPRATNE ARMIRANO BETONSKE ZGRADE PREMA EVROKODU I UPOREDNA ANALIZA DOMAĆIH I EVROPSKIH STANDARDA
}

\section{DESIGN OF MULTY-STOREY REINFORCED CONCRETE BUILDING BY EUROCODE AND COMPARATIVE ANALYSIS OF NATIONAL AND EUROPEAN STANDARDS}

\author{
Marko Novaković, Fakultet tehničkih nauka, Novi Sad
}

\begin{abstract}
Oblast - GRAĐEVINARSTVO
Kratak sadržaj - U radu je prikazan projekat višespratne armirano betonske zgrade spratnosti (Pr+7) na području Novog Sada, prema Evrokod standardima. U drugom delu rada prikazana je uporedna analiza proračuna zgrada prema domaćim propisima $i$ Evrokodu.
\end{abstract}

Ključne reči: Višespratna armirano betonska zgrada, upredna analiza, Evrokod.

Abstract - In this work is presented the project of multystorey reinforced concrete building $(G f+7)$ in the area of Novi Sad, according to Eurocode standards. In the second part of this work is represented comparative analysis of estimateo of the building, according to domestic and Eurocode standards.

Keywords: Multy-storey reinforced concrete building, comparative analysis, Eurocode.

\section{UVOD}

Projektnim zadatkom je predviđena izgradnja višespratne armirano betonske zgrade spratnosti $(P r+7) \mathrm{u}$ Novom Sadu, pravougaonog oblika u osnovi, a prema zadatom arhitektonskom rešenju. Fundiranje je izvršeno na temeljnoj ploči ojačanoj gredama. Noseća konstrukcija objekta projektovana je kao armirano betonska konstrukcija, sa AB međuspratnim tavanicama, $\mathrm{AB}$ stepenicama za vertikalnu komunikaciju i zidovima za ukrućenje. Podaci o dejstvima uzeti su u skladu sa namenom objekta kao i podaci o tlu u skladu sa lokacijom. Projektom su obuhvaćeni analiza opterećenja, proračun merodavnih uticaja, dimenzionisanje, neophodni konstrukcijski detalji, kao i planovi armiranja. $\mathrm{U}$ istraživačkom delu sprovedena je uporedna analiza proračuna $\mathrm{AB}$ zgrada prema Evrokodu i domaćim propisima.

\section{OPIS PROJEKTA}

\subsection{Arhitektonsko rešenje}

Objekat je provougaonog osnove dimenzija $54,92 \times 15.10 \mathrm{~m}$. U prizemlju se nalaze poslovni prostori, dok je ostali proctor predviđen za stanovanje. Sedam tipskih etaža predviđene su kao stambeni deo objekta.

\section{NAPOMENA:}

Ovaj rad proistekao je iz master rada čiji mentor je bio dr Đorđe Lađinović, red. prof.
Za vertikalnu komunikaciju predviđeno je stepenište I dva lifta. Prilikom odabira položaja stepeništa u zgradi jedan od uslova je bilo i d se seizmička platna iskoriste kao zvučna izolacija stepeništa. Kao krovno rešenje predviđen je ravan krov.

\subsection{Konstruktivni sistem}

Projektnim zadatkom predviđen je konstruktivni sistem kao armirano betonska zgrada, što znači da su noceći elementi ramovi (grede i stubovi) i međuspratne krstastoarmirane tavanice. Konstrukcija je dodatno okrućena i seizmičkim platnima i to u osama: 1 , 12 ,I oko lifta. Osna rastojanja u poprečnom pravcu variraju od 1.70 do $5.95 \mathrm{~m}$, a u podužnom od 3.5 do $7.4 \mathrm{~m}$.

Temelj je uradjen kao temeljna ploča debljine $50 \mathrm{~cm}$, ojačan temeljnim gredama dimenzija $50 / 125 \mathrm{~cm}$.

Stubovi su dimenzija 50/50 na svim etažama.

Dimenzije greda: $30 / 45 \mathrm{~cm}$

Seizmička platna su debljine $25 \mathrm{~cm}$. Međuspratna konstrukcija je AB puna ploča debljine $15 \mathrm{~cm}$.

Stepenice su formirane kao jednokrako stepenište Armirano betonsko delovi konstrukcije su izvedeni $\mathrm{u}$ klasi betona $\mathrm{C} 30 / 37$, a korišćen je čelika za armiranje B500.

\subsection{Analiza opterećenja}

Sopstvena težina konstruktivnih elemenata (grede, stubovi, zidovi, ploče...) automatski su generisani prema zadatim parametrima. Sopstvena težina nekonstruktivnih elemenata koji imaju karakter stalnog opterećenja (podne podloge i obloge, krov, pregradni zidovi, instalacije, opterećenje od tla i td.) imaju karakteristične vrednosti usvojene u skladu sa EN 1991-1-1:2002 [2] a potom dodatno aplicirane na model za proračun.

Korisna opterećenja, u zavisnosti od namene objekta i njegovih delova usvojena su prema EN 1991-1-1:2002, u ovom slučaju razmatrane su sledeće grupe prostorija: stamebi prostor; balkoni i stepeništa; hodnici; ostave; krov.

Opterećenje snegom je razmatrano za datu lokaciju, Novi Sad, čija je nadmorska visina oko $81 \mathrm{mnm}$, usvojeno je u skladu sa EN 1991-1-3:2003 [3], u iznosu od 1,2 kN/m² (na strani sigurnosti). 


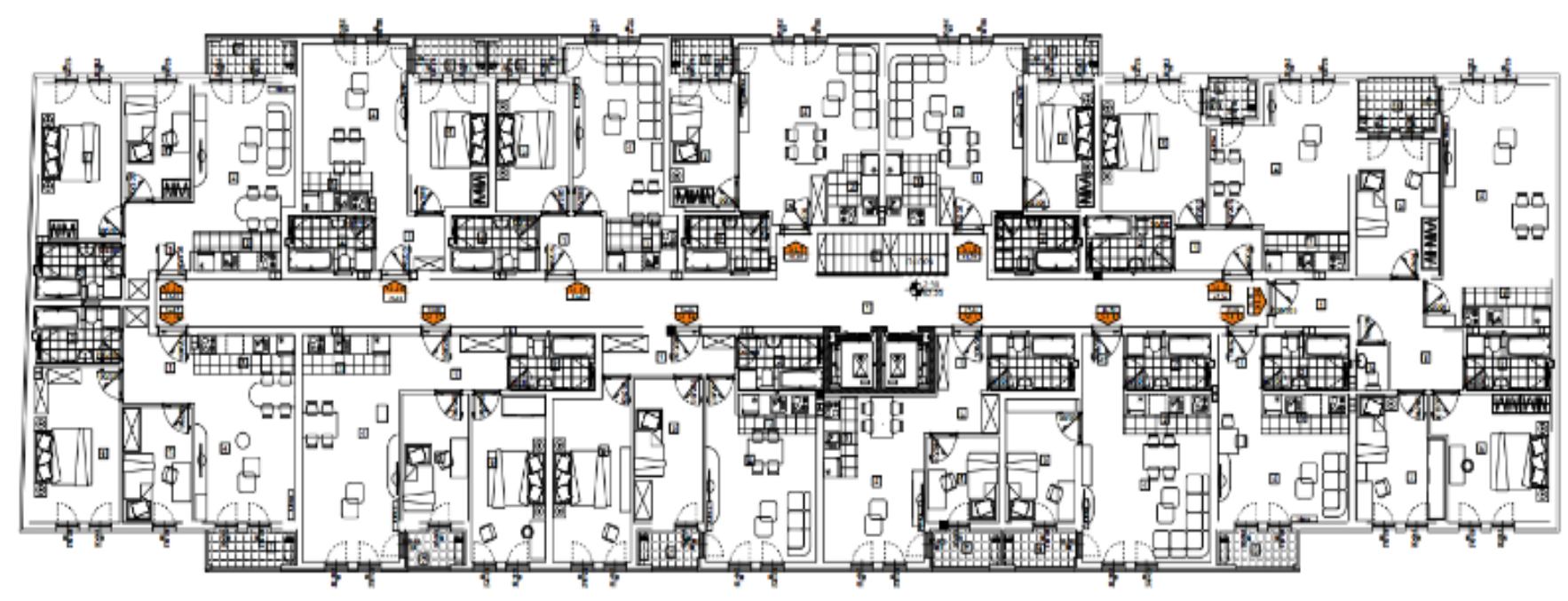

Slika 1. Tipska stambena etaža

Seizmičko opterećenje je generisano primenom softwera Tower 7.0, a u skladu sa EN 1998-1-2004 [5]. Za izračunavanje seizmičkih sila primenjena je multimodalna spektralna analiza - Metoda poprečnih sila.

\subsection{Statički i dinamički proračun}

Statički i dinamički proračun je izvršen primenom softverskog paketa Tower 7.0, primenom teorije prvog reda.

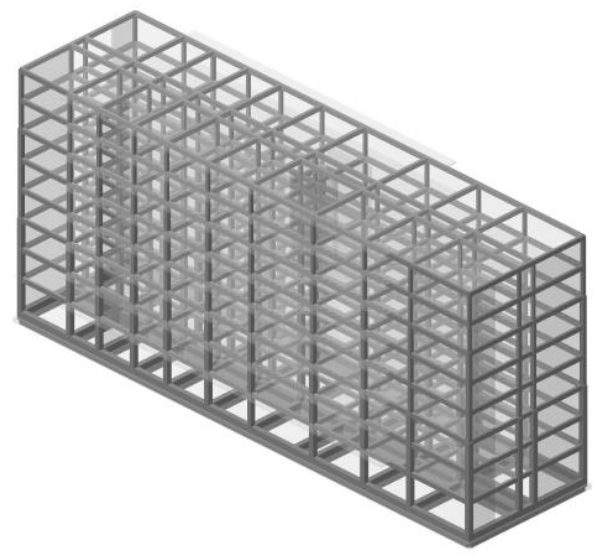

Slika 2. 3D model

Tlo je modelirano kao Vinklerov model [6] tla, što podrazumeva niz elastičnih opruga koje omogućavaju rad konstrukcije koja odgovara približno realnim uslovima. Prilikom modalne analize usvojene su pretpostavke da je međuspratna tavanica kruta $\mathrm{i}$ da su mase koncetrisane $\mathrm{u}$ nivoima tavanica, usvojeni su konačni elementi dimenzija $0,50 \times 0,50 \mathrm{~m}$ radi tačnijih rezultata.

Kao rezultat dinamičke analize modela dobijeni su periodi oscilovanja koji su dalje iskorišćeni pri seizmičkom proračunu, a za definisanje koeficijenata učešća masa za modalnu analizu korišćene su odredbe EN 1991:2002.

Za određivanje uticaja u nosećoj konstrukciji od dejstva seizmičkih sila primenjena je multimodalna spektralna analiza u saglasnosti sa odredbama EN 1998-1:2004, a proračun je sproveden primenom softverskog paketa Tower 7.0.

Prema seizmološkoj karti za predmetnu lokaciju objekta usvojeno je projektno ubrzanje tla u iznosu $a_{g}=0,15 g$, a projektni elastični spektar je konstruisan za kategoriju tla tipa „C“ i III kategorija objekta.

Za potrebe dimenzionisanja definisana su dva pravca delovanja seizmičkih sila u X i Y pravcu.

\subsection{Proračunske kontrole}

Sprovedene su proračunske kontrole u cilju potvrde kvaliteta odabranog koncepta konstrukcije. Izvršene su sledeće kontrole:

- Provera graničnog stanja nosivosti za nosivost tla, napon se kontroliše za dve kombinacije opterećenja.

\subsection{Dimenzionisanje elemenata}

Primenom softwerskog paketa izvršeno je dimenzionisanje prema kompletnoj šemi opterećenja, merodavne kombinacije opterećenja su automatski odabrane. Dimenzionisanje i armiranje elemenata je izvedeno prema EN 1992-1-1:2004 [4]. Zaštitni slojevi su definisani prema klasama izloženosti.

Dimenzionisani su svi AB elementi: ploče, stubovi, grede i seizmička platna.

Ploče su dimenzionisane serijama šipki. Krovna ploča, ploča tipskog sprata i prizemlja su armirani armaturom prečnika $8 \mathrm{~mm}$ a temeljna ploča armaturom prečnika 19 mm (donja zona) i $12 \mathrm{~mm}$ (gornja zona).

Poštujući sve odredbe i preporuke Evrokoda izrađeni su planovi armature za sve razmatrane elemente. Kao primer, prikazani su planovi armiranja temeljne grede, sl. 3 i sl.4. 


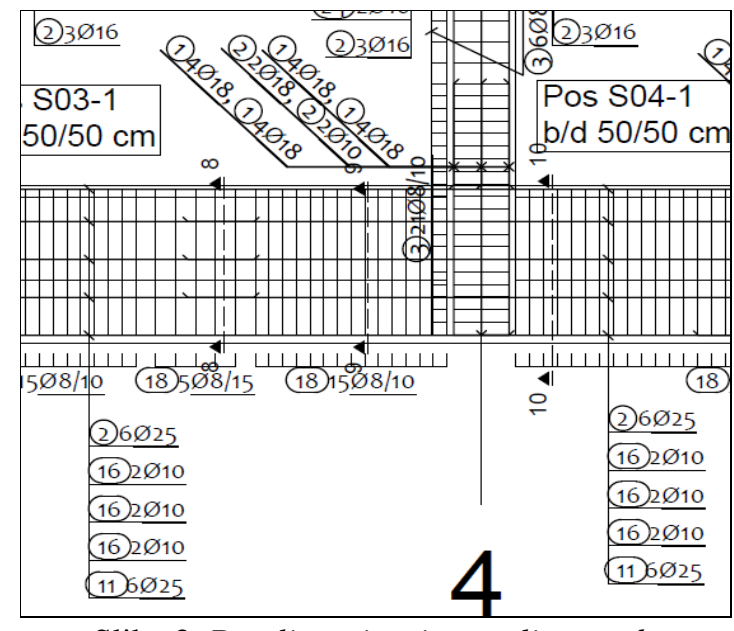

Slika 3. Detalj armiranja temeljne grede

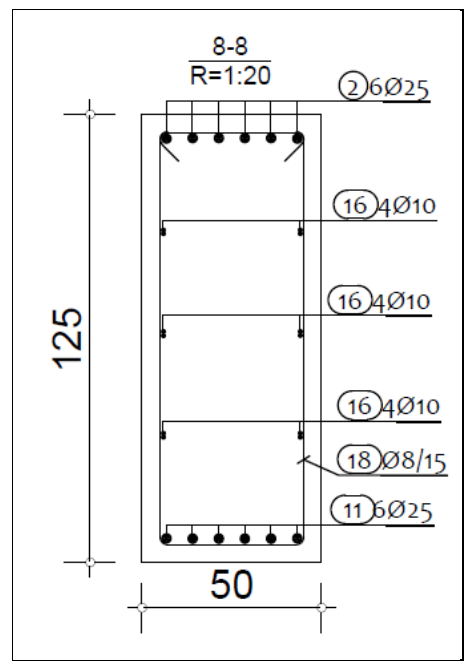

Slika 4. Poprečni presek temeljne grede

\section{UPOREDNA ANALIZA}

U okviru istraživačkog dela master rada zadatak je da se izvrši poređenje proračuna armirano betonskih konstrukcija prema Pravilniku o tehničkim normativima za beton (BAB) i proračuna armirano betonskih konstrukcija prema EN 1992.

Poređenje je sprovedeno teoretski uz opisivanje pojedinačno svakog koraka pri procesu proračuna. Uporednom analizom trebalo bi da se dođe do zaključka kolike su razlike (kvantitativno i kvalitativno) između domaćih (BAB) i evropskih (Evrokod) propisa.

\subsection{Analiza opterećenja}

Pored opterećenja stalnog karaktera koja su jednaka u oba slučaja, veoma bitnu su ona opterećenja koja su u funkciji namene objekta kao i opterećenja u zavisnosti od spoljnih uticaja (sneg i seizmičko dejstvo).

-Korisna opterećenja su ona koja se značajno razlikuju, te je uočeno da EN detaljnije razmatra moguće slučajeve te daje mogućnost boljeg definisanja opterećenja.

-Opterećenje od snega ima približno iste vrednosti,

-Dok se značajno razlikuje seizmičko opterećenje gde je kod domaćeg pravilnika za određivanje uticaja primenjena metoda statički ekvivalentnih sila, a u slučaju EN multi modalna spektralna analiza - metoda poprečnih ramova.

\subsection{Analiza materijala}

Prema domaćem pravilniku za armirano betonske konstrukcije primenio sam marku betona MB40, dok je po evropskim standardima EN1992 ekvivalent klasa betona c30/37.

Prema domaćem pravilniku korišćena je rebrasta armature RA400/500 a prema evropskim standardimaa (prema Evrokodu) korišćena je armature S500.

\subsection{Analiza elemenata konstrukcije}

Radi boljeg upoređivanja utrošene armature nisam menjao dimenzije elemenata.

-Tako da su dimenzije temeljnih greda: $50 / 125 \mathrm{~cm}$

-Dimenzije stubova: $50 / 50 \mathrm{~cm}$

- Dimenzije spratnih greda: $30 / 45 \mathrm{~cm}$

-Debljine seizmičkih platana su u oba slučaja debljine 25 $\mathrm{cm}$

\subsection{Analiza usvojene armature}

Upoređivanjem usvojene armature prema domaćim standardima i Evrokodu uočio sam da je više armature potrebno po Evrokodu kad je reč o gredama i stubovima, a po domaćim standardima je potrebno više armature $u$ pločama.

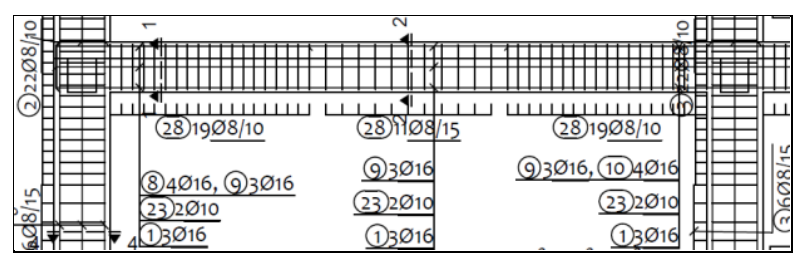

Slika 5. Plan armiranja tipske grede

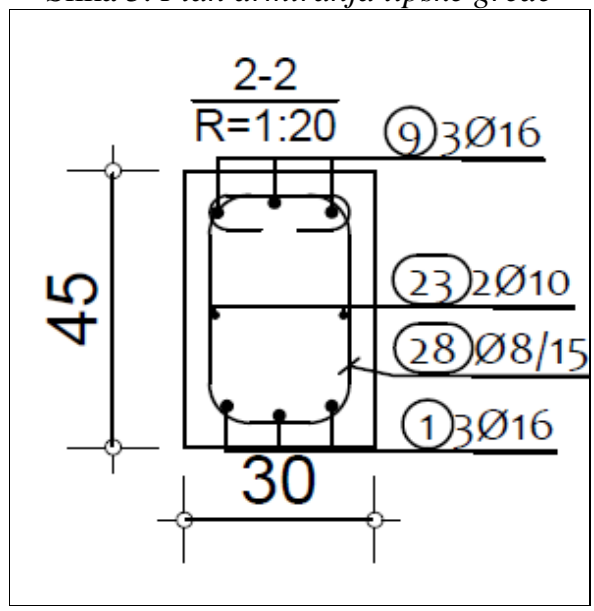

Slika 6. Poprečni presek tipske grede 


\section{ZAKLJUČAK}

$\mathrm{Na}$ osnovu svega gore navedenog, moguće je uočiti tri značajne razlike:

- Prva razlika odnosi se na vrednosti korisnih opterećenja zgrada - u evropskim standardima vrednosti opterećenja su malo veće nego u našim propisima, pa se mogu očekivati i razlike u veličini uticaja u nosećoj konstrukciji;

- Druga razlika se odnosi na seizmičku analizu i na proračun seizmičkog dejstva $-\mathrm{u}$ nacionalnim propisima se za proračun uticaja od seizmičkog dejstva koristi statički ekvivalentna metoda dok se u evropskim standardima proračun sprodvodi metodom multi modalne analize - metodom poprečnih ramova;

- Treća razlika je količina upotrebljene armature

Nakon određenih provera i proračuna došlo se do razlika veoma malih između ova dva standarda, što ukazuje da su naši standardi dovoljno dobri i precizni. Trebalo bi modifikovati malo domaće standarde I uvesti iz Evrokoda ono što valja, npr. analiza opterećenja za korisno opterećenje (preciznije je)

\section{LITERATURA}

[1] Pakvor Aleksandar, Perišić Života, Aćić Mirko, "Evrokod 0: EN 1990:2002. Osnove proračuna konstrukcija“.Prevod sa Engleskog jezika: dr Aleksandar Pakvor. Građevinski fakultet Univerziteta u Beogradu: Beograd 2009.

[2] Najdanović Dušan, "Evrokod 1: EN 1991-1-1:2002. Dejstva na konstrukcije; deo 1-1: Zapreminske težine, sopstvena težina, korisna opterećenja za zgrade“.Prevod sa Engleskog jezika: dr Aleksandar Pakvor. Građevinski fakultet Univerziteta $u$ Beogradu: Beograd 2009.

[3] Najdanović Dušan, "Evrokod 1: EN 1991-1-3:2003. Dejstva na konstrukcije; deo 1-3: Dejstva snega“.Prevod sa Engleskog jezika: dr Aleksandar Pakvor. Građevinski fakultet Univerziteta $u$ Beogradu: Beograd 2009.
[4] Dr Života Perišić, de Mirko Aćić, dr Aleksandar Pakvor, "Evrokod 2: EN 1992-1-1:2006. Proračun betonskih konstrukcija;“.Prevod sa Engleskog jezika: dr Života Perišić. Građevinski fakultet Univerziteta u Beogradu: Beograd 2006.

[5] Đorđe Lađinović, "Evrokod 8: EN 1998-1:2004. Proračun seizmički otpornih konstrukcija; deo 1:Opšta pravila, seizmička dejstva i pravila za zgrade“.Prevod sa Engleskog jezika: dr Lađinović Đorđe, dr Folić Radomir, dr Brčić Stanko, dr Brujić Zoran, dr Tatjana Kočetov Mišulić, Andrija Rašeta. Građevinski fakultet Univerziteta u Beogradu: Beograd 2009.

[6] Zoran Brujić: Betonske konstrukcije u zgradarstvu

\section{Kratka biografija:}

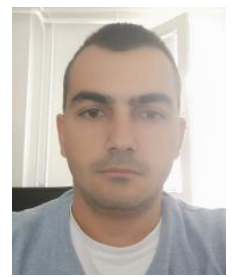

Marko Novaković rođen je u Bijeljini 1993. godine. Osnovne akademske studije završio je 2017. godine na Fakultetu tehničkih nauka u Novom Sadu. Master rad iz oblasti "Seizmička analiza konstrukcija" pod mentorstvom prof. dr Đorđa Lađinovića odbranio je 2019. godine.

Kontakt: novakovic.marko93 @gmail.com 